\title{
RE-TRAZAR EL HAIKU
}

\author{
Julia Jorge \\ Universidad Nacional de Córdoba \\ Instituto de Humanidades \\ Concejo Nacional de Investigaciones Científica y Técnicas \\ mariajuliajorgeauad@gmail.com
}

Resumen: El presente trabajo se ocupa de estudiar la materialidad del haiku japonés de principios del siglo XX. Luego de un panorama general de los estudios del haiku en Occidente, se ocupa de la presentación de una categoría teórico-analítica para abordar el haiku japonés: re-trazar. Sirviéndose de algunas nociones de la deconstrucción y recorriendo el problema de la traducción en dicho marco, el re-trazar se configura como un hacer que se sitúa entre la traducción y la crítica del haiku. Para poner en ejercicio dicha categoría se estudian algunos baiku de un poeta característico del periodo ya mencionado: Taneda Santōka.

Palabras clave: Poesía japonesa, Haiku, Traducción, Santōka, Siglo XX.

\begin{abstract}
The present paper studies the materiality of the Japanese haiku in the early 20th century. After giving a general overview of baiku studies in the West, it presents a theoretical-analytical category to address the Japanese haiku: re-trace. Through Jacques Derrida's notion of deconstruction and exploring the problem of translation in this context, re-trace is configured as a practice placed between translation and critical studies concerning haikus. To make use of this category, some of the haikus of a characteristic poet of the period, Taneda Santōka, will be examined.
\end{abstract}

Keywords: Japanese poetry, Haiku, Translation, Santōka, 20th century. 


\section{Introducción}

Diversos estudios de habla hispana han sistematizado el catálogo de reglas formales que el baiku ha adquirido durante su desarrollo histórico-literario, con lo que han definido esta "forma poética" o "genero poético". El espectro de definiciones podría sintetizarse: un poema de tres versos, con una estructura silábica de dos versos de cinco sílabas que abrazan a uno de siete; frecuentemente con un corte rítmico después del primer o segundo verso (kireji, palabra cortante), al que suelen sobreponerse dos imágenes, una de las cuales refiere simbólicamente a un momento preciso de la estación en el calendario (kigo, palabra estacional), sin rimas, sin metáforas, sin sujeto. Un breve poema de diecisiete sílabas que no dice nada en especial, un poema Zen que se presenta como pequeño satori o iluminación instantánea, un poema del instante que nombra lo que sucede aqui y ahora, o bien, el instante poético donde el poeta revela cierta sacralidad de la naturaleza.

Mucho se ha hablado del baiku como forma o género. Por tratarse de un conjunto de reglas formales a las que se sumaba una expresión Zen que hacía del baiku una rareza para los ojos occidentales de principios de siglo XX. ${ }^{1}$ Sin embargo, la crítica

${ }^{1}$ Hay en este punto cierta subestimación de los poetas japoneses, porque hay una confusión sobre las tendencias clásicas con las más contemporáneas. No puede compararse la escritura de un monje poeta del siglo XVI como Bashō con la escritura de un monje hambriento y peregrino de tierras devastadas por la guerra y la modernización como Santōka. Sin embargo, hay que revisar la aplicabilidad de estos conjuntos de reglas cuando se avanza sobre poéticas que reciben el nombre de "baiku" a principios de siglo $\mathrm{XX}$, ya que estas tienen como fin determinar y evaluar la construcción correcta del baiku.

N 9. Segundo Semestre de 2018 
del baiku suele agotarse en la descripción de los trayectos biográficos de cada poeta, en la aplicación o no aplicación de las pautas formales como criterios de evaluación y de la interpretación fabulada de lo que ha visto el poeta, en algunos casos, sin sospechar la posibilidad ficcional de toda escritura. Además, la actividad crítica parece desvincularse de la actividad traductora, como si estas tareas corrieran por carriles paralelos con pocos puentes de comunicación. En el caso de la poesía en lengua japonesa, parece que la traducción debería alcanzar un alto nivel de fidelidad al original para recién desde allí abordar la pertinencia del poema a la forma haiku y enunciar algo sobre este.

Ahora bien, las brechas se agravan ante poéticas modernas que han transgredido por voluntad propia toda pauta formal sin dejar de auto-nombrarse con el nombre haiku. Estas son resultado del proceso de Restauración Meiji (1868-1912). ${ }^{2}$ La influencia del arte occidental, la inminente extinción de las artes tradicionales, los sucesivos impactos del paso de una sociedad rural a una industrializada y los nuevos circuitos de circulación de la literatura dan paso a múltiples procesos

\footnotetext{
${ }^{2}$ La Restauración Meiji fue el periodo de modernización de la sociedad rural japonesa en una sociedad industrial con la formación del Estado nacional unificado. Entre sus acontecimientos más importantes se cuentan el fin del aislamiento japonés a Occidente y la intervención del shogunato Tokugawa (grupo de jefes militares) por parte de la elite japonesa, así como la devolución del poder al emperador. Si bien, la cadena de acontecimientos que condujeron a la restauración se desarrolló entre los años 1866 y 1869, se considera que la era Meiji se estabilizó recién hacia 1912 aproximadamente.
} 
estéticos de restauración de las formas y del lenguaje, a lo cual el haiku no escapa. ${ }^{3}$

Entonces, se podría determinar un pequeño gesto de vanguardia en las producciones de baiku de esta época solo y en cuanto las trasformaciones que sufrió el haiku en esta época se debieron a la renovación de las formas del lenguaje, lo que significó el abandono de formas simbólicas y retóricas o su desestimación. Además, la singularidad de estas poéticas es que no no tendrán carácter testimonial (es decir, el baiku como el registro de lo acontecido), sino que estarán orientadas a repensar su propia materia, esto es, la escritura japonesa, como aquello auténticamente japonés de esta forma poética codificada y pensada para ser exportada a Occidente. Algunos de los poetas del haiku más destacados de este proceso fueron Masaoka Shiki (1867-1902), Taneda Santōka (1888-1940), Ozaki Hōzai (1885-1926), Ogiwara Seisensui (1884-1976), poetas que se nuclearon en torno a la revista actualmente en circulación Hototogitsu (1987). Sus poéticas comparten una característica desatención a la estructura formal y revelan un

\footnotetext{
${ }^{3}$ La producción teórica y poética de Masaoka Shiki (1867-1902) evidencia la cuestión. En la revista de haiku Hototogisu (Cocú, 1897), declaró tres principios fundamentales para un proceso estético que denominó como restauración del haiku: "(1) el baiku es literatura; (2) el baiku debe ingresar en la realidad; (3) los maestros del viejo estilo del baiku deben ser remplazados si se quiere que el baiku sobreviva." (Cuartas Restrepo, 2005: 173). Esta declaratoria respondía a la inminente extinción de las formas poéticas tradicionales y a la vez garantizaba su supervivencia en cuanto convivían con los nuevos modelos literarios occidentales (especialmente la novela realista). Para ello se propuso la tarea de desendiosar los poetas clásicos como Bashō y asimilar nociones de la filosofía occidental (como su uso de la teoría Spencer para determinar la imprescindible economía mental para escribir haiku, para sostener su propia teoría del haiku se basa en el concepto de shasei, definida como esbozo de vida, simpleza y estilo íntimo (cfr. Cuartas, 2005).
}

$N^{\circ}$ 9. Segundo Semestre de 2018 
trabajo singular con la escritura japonesa. Ahora bien, ¿cómo dar cuenta de las posibilidades y singularidades de sentido de lo que está escrito no solo en otra lengua sino también en otra escritura?, Una que no tiene su origen en la representación fónica del habla, sino que es próxima a la representación de la idea, figurativamente la cosa, el espacio, la acción.

Teniendo en cuenta lo anterior, puede sostenerse que la validez de la pregunta por la definición, el qué, se esfuma en el momento en que aparece la pregunta por el cómo: ¿cómo avanzar sobre el haiku, sobre la escritura japonesa y sobre los diferentes recorridos poéticos de cada uno de estos poetas modernos? La apuesta del presente trabajo es ensayar una respuesta a esta pregunta. Esta cuestión conduce directamente a configurar un modo de leer el haiku que debe detenerse en las posibilidades de traducción de la lengua, pero especialmente en la traducción de una escritura a otra escritura. Es decir, no solo se trata de un trabajo de interpretación y traducción de lo producido en una sensibilidad y episteme oriental (considerada durante mucho tiempo como opuesta a la occidental), sino también de dar cuenta de la potencia de la materia de la que se sirven. La configuración de este nuevo modo de leer permite decir algo al respecto del baiku. Esto es hacer crítica del baiku con la determinación de las diversas especificidades de cada poética. Para configurar dicho modo de leer se propone revisar algunas nociones y problemas que se desprenden de la deconstrucción de Jacques Derrida, ya que su pensamiento permite repensar la escritura japonesa y su traducción desde puntos singulares. Desde allí, se avanzará sobre la configuración de la categoría teórica analítica del re-trazar para 
seguidamente ejercitarla sobre uno de los baijin ${ }^{4}$ con más repercusión tanto en el archipiélago nipón como en Occidente, Taneda Santōka (1882-1940). ${ }^{5}$

\section{Prejuicio chino}

Ahora bien, ¿cómo llevar adelante la aventura de la deconstrucción en el haiku? El pasaje de la deconstrucción a otro marco cultural conduce a detenerse en el problema de la traducción, el cual resulta indispensable para aproximarse a la escritura japonesa. La propuesta deconstructiva sobre la traducción es una forma de leer el sentido del haiku sin dejar de lado la complejidad de la escritura no-alfabética, especialmente aquella que funciona como materia del haiku. Por ello, antes de avanzar sobre el problema de la traducción deben revisarse algunos puntos fundamentales del pensamiento derrideano sobre estas otras escrituras.

Para comprender la singularidad de la escritura japonesa es conveniente partir de lo que Jacques Derrida en "De la

${ }^{4}$ Haijin (俳句): poeta del baiku.

${ }^{5}$ Santōka (山頭火 literalmente, Montaña de fuego) fue el seudónimo de Taneda Shōichi (Hofu, 1882 - Matsuyama, 1940), uno de los poetas con más repercusión en el Japón de la posguerra. Su contacto con la literatura occidental se produce tempranamente como traductor: en 1911, publica en la revista Seinen (Juventud) una serie de traducciones de Iván Turguénev y Guy de Mauppassant. En 1913, se integra a Jiyuritsu y, meses más tarde, se hace editor y colaborador de la revista Sounn. Publica en vida tres colecciones de haiku: El niño del cuenco (Hachi no ko, 1932), Torre de vegetación (Somokuto, 1933) y Senderismo por la linea del agua (Sankōsuikō, 1935)

$N^{\circ}$ 9. Segundo Semestre de 2018 
gramatología como ciencia positiva" (1986) explica como el prejuicio chino y/o prejuicio jeroglifista. Para definir los límites de la gramatología, Derrida recorre textos de pensadores occidentales que han detectado en la escritura no-alfabética una lógica contraria al logocentrismo. Frente al oirse-hablar de la sustancia fónica (que vehiculiza la presencia, el ego, el pensamiento) la escritura china ostenta la ausencia o la articulación arbitraria de la escritura con la voz, lo que significa la expresión radical de la escritura como técnica. La ausencia de un vínculo entre la escritura ideográfica y la voz definió el lugar de la escritura nofonética para Occidente. Derrida ejemplifica dicha cuestión refiriendo al modelo chino de Gottfried Leibniz. Desde el siglo XVII, Leibniz comprendió que la escritura china constituía un modelo de lengua que estaba exenta de la lógica-lineal del alfabeto, por lo cual se sustraía a la historia y la hacía propicia para un razonamiento filosófico:

En todo caso esta es la función del modelo chino en los proyectos de Leibniz. A su juicio lo que libera la escritura china de la voz es también lo que, por la arbitrariedad y el artificio de la invención, la arranca a la historia y la hace propicia para la filosofía. (Derrida, 1986, p. 100)

Arbitrariedad y artificio de la invención. Es decir, se trata de la definición del ideograma por la suspensión de la unidad entre la palabra y el sentido, a lo cual, suma Derrida: "Este carácter arbitrario tiene un vínculo esencial con la esencia no-fonética que Leibniz cree poder atribuirle a la escritura china" (Derrida, 1986, p. 105). La arbitrariedad creativa del ideograma se figura como amenaza cuando se lee bajo la lingüística estructuralista. Derrida retoma el Curso de lingüistica general (1916) de Ferdinand de Saussure, quien definía la instrumentalidad de la escritura 
fonético-alfabética (en cuanto utiliza elementos irreductibles al babla), pero también comprendía la instrumentalidad de la escritura ideográfica, aunque sin dejar de expresar la relación opositiva con la alfabética. En este sentido, la escritura ideográfica no expresa directa o inmediatamente el habla, sino que expresa indirectamente la idea, alejándose doblemente del habla, es decir, sin pasar nunca por ella:

El sistema ideográfico, en el cual la palabra está representada por un signo único y ajeno a los sonidos de que se compone. Ese signo se refiere al conjunto de la palabra, y de ahí, indirectamente, a la idea que expresa. (Derrida, 1986, p. 43)

En este sentido, Derrida entiende que la formulación sobre la escritura como sistema de signos arbitrarios no puede articularse en términos ni simbólicos ni figurativos. De este modo, la escritura china se presenta contradictoria para Saussure, en cuanto este grafismo conserva "una relación de figuración natural y de cierto parecido con lo que ya no es significado sino representado, dibujado, etc." (Derrida, 1986, p. 43).

Pero veremos que dicha arbitrariedad o ausencia deviene de modo singular en la escritura japonesa, la cual es a la vez ideográfica y fonética. Utiliza los ideogramas (kanji) heredados de China y a la vez utiliza el silabario (biragana) para la expresión de palabras de origen japonés, onomatopeyas, abreviaciones. ${ }^{6}$ Sin embargo, dicha arbitrariedad o ausencia de

\footnotetext{
${ }^{6}$ Además, el japonés suma los ideogramas chinos otros de invención propia, que se basan en los componentes de los ideogramas ya dados. También, existe otro silabario en japonés denominado katakana que sirve exclusivamente para transliterar palabras extranjeras.
} 
relación entre habla y escritura está articulada por una relación con la naturaleza. Incluso es ella la que da y se sirve de la voz. Esta idea de escritura natural no debe entenderse en términos de una escritura pneumatológica, es decir, la escritura unida a la voz y al aliento vinculada a la escritura divina o sagrada (Derrida, 1986, p. 24). Esta comprensión muestra la diferencia entre una escritura buena y natural y la perversa y artificiosa: "la técnica, exiliada en la exterioridad del cuerpo" (Derrida, 1986, p. 24). En este sentido, la escritura japonesa es una técnica. Deja es(ins)cribir a toda una civilización que no había desarrollado previamente un sistema de escritura homogéneo. La correspondencia entre voz y escritura no existe, la distancia entre ambos términos es más que lejana, lo que afecta al modo de significación.

Derrida discute para las escrituras no-fonéticas su posibilidad de representar, pseudo-miméticamente, la naturaleza del mundo. Dicha hipótesis parte de confusión entre la escritura ideográfica y la pictográfica. Derrida observa en el sinólogo Jacques Gernet una nueva operación logoscentrista. Para Gernet, la escritura china conserva un prestigio primitivo que se debe al vínculo de la escritura con una realidad única y singular. Pero esta operación hace entrar al modelo chino nuevamente en el marco logocéntrico, ya que (al igual que el habla) se vincula la escritura china con "lo único" y lo "singular", es decir, con lo inmutable y lo sustancial. (Derrida, 1986, p. 123). Derrida comprende que la complejidad de las escrituras primitivas reside en que comportan desde muy temprano elementos fonéticos, los cuales fueron dominados por el 
ideograma o el álgebra. ${ }^{7}$ Para Derrida, ello da cuenta de "el testimonio de un poderoso movimiento de civilización desenvolviéndose al margen de todo logocentrismo. La escritura no reducía la voz en sí misma, la ordenaba en un sistema" (Derrida, 1986, p. 122). La interrogación de Derrida a Gernet se muestra aquí ¿por qué nuevamente vincular la escritura con una condición de idealidad que parece equipararse con la presencia y el habla occidental? En este sentido, Derrida realiza una relevante articulación entre la escritura china y la repetición, movimiento constitutivo de uno de los conceptos principales de la deconstrucción: la huella. La repetición es aquella condición de su idealidad, que constituye la escritura china como significante y, a la vez, la desvincula de esa realidad "única" y "singular":

Un significante es, desde el comienzo, la posibilidad de su propia repetición, de su propia imagen o semejanza. Es la condición de su idealidad, aquello que lo hace reconocer como significante y lo hace funcionar como tal, vinculándose a un significado que, por iguales razones, nunca podría ser una "realidad única y singular". Desde que aparece el signo, vale decir desde siempre, no hay ninguna posibilidad de encontrar en algún lugar la pureza de la "realidad", de la "unicidad", de la "singularidad" (Derrida, 1986, p. 123).

\footnotetext{
${ }^{7}$ Debe recordarse que la escritura japonesa es heredada de China y luego ampliada con el silabario para representar los sonidos que la escritura china no representaba; por ende, la lengua debió adecuarse a un sistema de escritura que no se correspondía gráficamente con su expresión fonética.
} 
Debe subrayarse que la escritura no-fonética tiene en su origen también la repetición característica de la buella. La escritura no es la pureza de una realidad singular y natural, sino que retiene su vacío. Desde aquí ya podemos comenzar a comprender el ideograma como el significante que no tiene ningún vínculo natural con el significado, sino que lo rompe supliendo la naturaleza por el vacío. La huella cuestiona la naturalidad en sí misma. Al pensar en la escritura japonesa como huella se la conduce hacia el significante: "La huella instituida es 'inmotivada' pero no caprichosa. (...) Simplemente no tiene ningún 'vínculo natural' con el significado en la realidad. La ruptura de este 'vínculo natural' cuestiona, para nosotros, la idea de naturalidad, más que la de vínculo" (Derrida, 1986, p. $60)$.

Para Derrida la escritura funciona acorde al movimiento de la huella, es decir siguiendo la lógica del suplemento, vaciando todo lo que permanezca en su centro y supliéndolo:

La buella es, en efecto, el origen absoluto del sentido en general. Lo cual equivale a decir, una vez más, que no hay origen absoluto del sentido en general. La buella es la différance que abre el aparecer y la significación. Articulando lo viviente sobre lo noviviente en general, origen de toda repetición, origen de la idealidad, ella no es más ideal que real, más inteligible que sensible, más una significación transparente que una energía opaca, y ningún concepto de la metafísica puede describirla. (Derrida, 1986, pp. 84-85)

En este sentido, la escritura japonesa sigue también el juego de la huella. En un primer lugar, porque la escritura japonesa al vincularse con el vacío como movimiento que expropia la cosa 
de su origen, reconoce de antemano el concepto de huella. En este sentido, no hay limitación del juego. Además, porque un pensamiento sobre la escritura no-alfabética, específicamente la japonesa, ya ha agotado (desde su origen heredado, incluso) el significado trascendental del signo: "Se podría llamar juego a la ausencia de significado trascendental como limitación del juego, vale decir como conmoción de la onto-teología y de la metafísica de la presencia" (Derrida, 1986, pp. 64-65).

En este sentido, la escritura habilita un juego donde el movimiento de la huella le es constitutivo. Diremos, para el japonés: el trazo no depende de un significado pleno, sino que señala su pertenencia al orden del vacío dado por la repetición. Cada trazo de la escritura japonesa remite a otro trazo y el sentido de ese trazo a otro sentido con otro trazo. La escritura muestra en sus trazos toda posibilidad de sentido, ahí donde se tensiona haciendo ver lo intraducible de una lengua por ella misma. Este es el proceso poético fundamental del haiku y donde ingresa el problema de la traducción.

\section{Hacer advenir la lengua}

En la respuesta a la pregunta "Che cos'è la poesía?" (1988), Derrida reflexiona y sostiene que la poesía se define en un movimiento de exposición y retracción de la palabra en el poema. Este es explicado a través de la figura del erizo: aquel animal que al verse amenazado por el accidente se enrolla sobre sí 
mismo ${ }^{8}$. El poema funcionaría de un modo análogo al animal: se expone a la apertura del sentido de las palabras, pero a la vez, en su retroacción, refiere a una autenticidad del poema que no depende de un yo. El poema que se enrolla, como el erizo, saca afuera todos sus enigmáticos signos que son huellas que suscitan el deseo de apropiación del poema. A este deseo de apropiación, Derrida lo denomina apprendre par coeur (que en francés significa literalmente aprender de corazón, pero se usa para referir a la memorización). En este punto comenzamos a dilucidar la cuestión de la traducción. Primero, esos enigmáticos signos del poema están inscriptos en el movimiento de la huella. Es decir, su origen es la repetición por la repetición, lo que Derrida denomina en este texto como literalidad. La literalidad solo puede aprehenderse de corazón y de memoria, porque en ese vínculo sellado entre el sentido y la letra:

Literalmente: querrías retener par coeur [de memoria] una forma absolutamente única, un acontecimiento cuya intangible singularidad no separe más la idealidad, el sentido ideal, como se dice, del cuerpo de la letra. En el deseo de esta inseparación absoluta, en el absoluto noabsoluto, respiras el origen de lo poético. (Derrida, 1995, p.43)

Además, Derrida agrega que el poema está bajo el dictado de lo Otro, como el erizo está expuesto al accidente. Eso Otro

\footnotetext{
${ }^{8}$ De allí su primera respuesta a la pregunta por la poesía:
}

Se ve dictado, lo respondido, por ser poético. Y por eso tiene que dirigirse a alguien, singularmente a ti pero como al ser perdido en el anonimato, entre ciudad y naturaleza, un secreto compartido, a la vez público y privado, absolutamente lo uno y lo otro, absuelto desde dentro y desde fuera, ni lo uno ni lo otro, animal arrojado a la ruta, absoluto, solitario, enrollado en una bola próximo a sí. Por esto mismo, justamente, puede hacerse pisar, el erizo, istrice. (Derrida, 1995, p.42) 
puede ser la otra lengua, en este caso, el japonés. La otra lengua amenaza el poema, pero a la vez está amenazado por él. Del mismo modo, el erizo está amenazado por el accidente en la ruta, pero a la vez (al ovillarse y mostrar sus espinas) amenaza. En este sentido, Derrida escribe sobre el poema: "No hay poema sin accidente, no hay poema que no se abra como una herida, pero también que no sea hiriente." (Derrida, 1995, p.43).

El sentido intraducible que viene con lo otro, con el accidente, es lo que se desea aprender, de corazón y de memoria en su literalidad, pero no se puede traducir o dicha traducción es inventada e improbable:

¿No es eso ya, el poema, cuando se da una prenda, la llegada de un acontecimiento, en el instante en que la travesía del camino llamada traducción permanece tan improbable como un accidente, a pesar de ello intensamente soñada, requerida allí donde eso que ella promete siempre deja algo que desear? (Derrida, 1995, p. 43)

Entonces, en la poesía hay algo que no puede traducirse. En esta línea puede interpretarse lo que Derrida explicaba en "Carta a un amigo japonés": "Cuando hablo de esa escritura de lo otro que sería más bonita, me refiero, evidentemente, a la traducción como el riesgo y la suerte del poema. ¿Cómo traducir 'poema', un 'poema'?' (Derrida, 2016, p. 471). Esta pregunta conduce a otra: cómo traducir una lengua dentro de la misma lengua, es decir: ¿cómo traducir del japonés al japonés? Entendiendo por traducir un juego que sigue el movimiento de la huella (lo que determina la remisión constante de la palabra a otro significado, haciendo que el 
significante nunca esté presente en sí y no se remita más que a sí mismo) hecha de trazas que han dejado en ella otros elementos. En el caso del japonés esas trazas no son simplemente el sonido sino también los trazos, los conjuntos de trazos, las imágenes que forman y sus remisiones a otros ideogramas. Hay que ir a la escritura para ver aquello que no solo permanece inaudible sino también invisible?

Para Derrida, la traducción (como juego) conlleva todo el trabajo de la deconstrucción en cuanto consiste en la obstinación por hacer advenir al sentido, por lo cual posee una fuerza creativa. En "Torres de Babel", Derrida cuestiona el problema de la traducción a partir del texto "La tarea del traductor" de Walter Benjamin en relación con el mito de Babel sobre el origen de las lenguas. La hipótesis central del texto de Derrida se articula en torno a la promesa de traducción. Esta consiste en que toda traducción promete restituir el sentido del texto original. Siguiendo a Benjamin, Derrida reconoce que dicha restitución consiste en la reconciliación de las lenguas y que la traducción debe garantizar la supervivencia de un sentido original.

Teniendo en cuenta esta idea, Derrida hace ingresar la traducción en el orden de una economía: el responsable de

\footnotetext{
9 En "La différance" (1994), Derrida afirma que no bay ninguna escritura puramente fonética dado que los signos gráficos (por ejemplo, los de puntuación o los espacios) son nofonéticos. De este modo, pone en tela de juicio el concepto de signo saussureano: si la diferencia es lo que define al signo, dicho juego es inaudible; pero, aun así, ese inaudible es lo que define al signo y lo deja operar como tal. Escribe Derrida: "Si no hay, pues, una escritura puramente fonética, es que no hay phoné puramente fonética. La diferencia que hace separarse los fonemas y hace que se oigan, en todos los sentidos de esta palabra, permanece inaudible" (Derrida, 1994, p. 41).
} 
restituir un sentido original está en deuda con el texto original. Pero dicho texto original siempre posee nombres que (en su carácter de buellas) remiten a una lengua original de la que solo se conserva un nombre, Babel", el cual reúne tanto la bendición de Dios (de multiplicar las lenguas) como el castigo (a la familia semítica por querer nombrar a Dios). Así, ese nombre tiene un sentido intraducible (castigo) pero a la vez su letra se anuncia traductible (bendición, de conservar el nombre Babel y la posibilidad de este de ser nombre propio y sustantivo: confusión):

Y como ningún sentido puede distinguirse, transferirse, transportarse y traducirse como tal (como sentido) en otra lengua, rige también la traducción que parece descartar. Es traductible e intraducible. Solamente hay letra, y esta es la verdad del lenguaje puro, la verdad como lenguaje puro. (Derrida, 2016, p. 252)

Observemos la relación entre ese sentido intraducible y el sentido inhallable de la poesía que debe aprenderse de memoria o de corazón. Ahora bien, ¿qué hacer entonces con lo traductible? Aquí la traducción hace otra pregunta: ¿cómo hacer devenir lo intraducible como traductible y cómo traductir el japonés dentro del japonés incluso desde nuestra propia lengua?

En este punto, tenemos que dirigimos hacia el borde de la lengua. En una entrevista en torno a Paul Celan (poeta de habla alemana de origen judío-rumano), "La lengua no pertenece" (2001), Derrida se acerca a esta cuestión explicando el modo en que este poeta realiza una interpretacióntraducción poética en una lengua que le es propia (el alemán). 
Para Derrida, Celan hace advenir la lengua tras múltiples movimientos de apropiación que la marcan, la hieren, le hacen mostrar su borde:

Creo que Celan ensayó una marca, una firma singular que fue una contra-firma de la lengua alemana y al mismo tiempo algo que adviene a la lengua alemana -que adviene en los dos sentidos de este término: que se aproxima a la lengua alemana, que acude a ella, sin apropiársela, sin someterse a ella, sin entregarse a ella, pero al mismo tiempo haciendo que la escritura poética advenga, es decir sea un acontecimiento que marque la lengua. (Derrida, 2001).

Este advenir implica no solo el reconocimiento de una impropiedad de la lengua, sino que también hace un pasaje de la lengua por la lengua. En dicho pasaje se encuentra una fuerza presionada por las formas de la lengua. Solo quien usa una lengua como impropia puede reconocer esta fuerza. Este hacer advenir implica marcar la lengua, resucitar aquello que en ella está muerto, esto es, crear (como dar vida nuevamente). Toda traducción debe reconocer la diseminación $n^{10}$ del sentido, la que hace acontecer lo ilegible como condición de legibilidad de un texto. Lo intraducible, lo inhallable del sentido, la repetición de la huella son condiciones (de legibilidad) que posibilitan una traducción para (re)crear ese texto. Esto es, volverlo a escribir para inscribirlo en el movimiento de la huella. Esto es lo que se intenta hacer con el japonés: ir hacia la escritura para marcar

${ }^{10}$ Cabe aclarar que la diseminación es una de las nociones claves del pensamiento de la deconstrucción. De manera sintética, creemos que la mejor forma de definir esta idea es en relación con el haz de fuerzas que involucra la différance. La iterabilidad del signo, su repetición infinita (y el constante descentramiento de significado), produce una permanente alteración, lo que significa cierta polisemia universal y constante. Esta operación es denominada por Derrida como diseminación. 
esos lugares donde lo intraducible se revela traductible. Esta es la promesa del presente escrito, como parece inquirir Derrida: "hay que cultivar el idioma y la traducción, hay que habitar sin habitar, hay que cultivar la diferencia lingüística sin nacionalismo, hay que cultivar la propia diferencia y la diferencia del otro" (Derrida, 2001).

\section{Re-trazar}

¿Cómo traducir en una lengua que no pertenece, pero que es nuestra única lengua? Es entre estos dos pliegues donde este trabajo ancla sus obsesiones. Ese algo que las lenguas no pueden alcanzar separadamente, sino solo a través del trabajo de reconciliación de las lenguas, a través de una traducción que se ocupe de la resistencia del texto, una traducción que cree, que haga advenir el sentido, ya que es allí donde se abre la posibilidad de toda crítica. Ahora bien, la tarea de una crítica poética sería la de exponer la fuerza de significación del baiku, fuerza que consiste en los múltiples movimientos de apropiación del fondo vacío de la lengua, de lo que está en su límite. Se trata de un hacer. Para que la escritura poética advenga hay que marcar un acontecimiento de lengua. En el haiku, lo dado apenas es unos cuantos ideogramas.

En ellos (en una lengua que no pertenece) deben tantearse las fallas, las marcas, las hendiduras. Se trata de una danza equilibrista sobre el entre los pliegues donde se funda lo intraducible. ¿Qué hay ahí? Buscaríamos un sentido que lata en una frecuencia similar a la enunciada por quien se deconstruye: 
Puesto que es en el borde del [japonés] francés, únicamente, ni en él ni fuera de él, sobre la línea inhallable de su ribera, donde, desde siempre, permanentemente, me pregunto si se puede amar, gozar, orar, reventar de dolor o reventar a secas en otra lengua o sin decir nada de ello a nadie, sin siquiera hablar. (Derrida, 1997, 14)

Pues sí: igozar y reventar de dolor en el límite intraducible de una lengua como el japonés! Pero debe afirmarse contundentemente que, en ese límite, hay que reinventarse en lo otra lengua cargando con la imposibilidad de la traducción fiel y original. Ese es el desafío de una traducción que tiene por meta la interpretación y la crítica a través de un trabajo que se hace sin credos. Es decir, sin dar fe de cierta fidelidad al original, ya que esa imposibilidad es constitutiva del haiku: se dona a la repetición con la voluntad de diseminar el sentido. La intraducibilidad del japonés (es decir, la imposibilidad de traducción dentro de una misma lengua) es la condición de legibilidad del baiku, condición que permite dar rienda suelta al trabajo de traducción-deconstrucción de la escritura japonesa, con la garantía de un porvenir del sentido necesario e inherente al haiku. Esta condición para el haiku debe nombrarse como: re-trazar, encuentro que implica volver a escribir haciendo advenir el sentido y dando paso a la fuerza creativa de toda traducción.

La operación del re-trazar está condicionada por la problemática de la traducción del haiku. Por ello, no atiende tanto a la traducción en español cuanto a los sentidos inscriptos en el ideograma de la escritura japonesa. El re-trazar se detiene donde encuentra las relaciones posibles de la escritura con lo sensible, dado que allí se producen 
singularidades del sentido. En este sentido, el re-trazar es una operación de lectura que se enfrenta y discute con los obstáculos presentados para leer el haiku, principalmente el de la traducción y la imposibilidad de recuperar una sensibilidad japonesa. En este sentido, el re-trazar no traduce ni descifra, sino que es un hacer que consiste en volver a escribir o volver a trazar el baiku.

El re-trazar se compone de dos operaciones fundamentales: la primera consiste en determinar el punto de fisura del baiku o un pliegue disonante donde deviene lo que no puede traducirse sin más. Es decir, un punto en el baiku que merece un rodeo, algo más que una simple palabra para ser traslada a otra lengua. La segunda operación intenta determinar el punto anterior a través de un des-trazo (desmontar la escritura del haiku) para volver a reunir esos trazos con el fin de explicar y describir dicho sentido, es decir, reunir nuevamente los sentidos inéditos del baiku y ordenarlos a manera de insistencias bajo el nombre de una poética.

Como puede notarse, el re-trazar nombra la operación de lectura con la que abordamos el baiku. Para mostrarla en su máxima expresión conviene ponerla a operar. Para ello, hemos seleccionado algunos baiku de Taneda Santōka, haijin de principios de siglo $\mathrm{XX}$, quien se destaca entre sus congéneres por haber roto la estructura formal de esta forma poética para dar lugar a complejidades de sentidos propias de su época. Entonces, trascendiendo las diferencias con las poéticas del baiku tradicionales, puede comenzarse este recorrido mencionando el profundo compromiso de Santōka con una escritura errante. Monje zen peregrino y mendicante en medio 
de una cultura finisecular que observa el aceleramiento cultural y el ingreso de la cultura occidental de forma fatalista. ${ }^{11}$ Esta circunstancia es llevada por Santōka a su modo de escritura, en ella no hay dirección, ni plan ni destino. Su poética, a diferencia de las tradicionales, esquiva al nombre propio, las palabras utilizadas para referir a la estación siempre son imprecisas; su cuerpo nunca encuentra el frescor de una estación. ${ }^{12}$ Todo lo contario, la poética de Santōka se conforma de dolores, heridas, de danzas poco coordinadas, de músicas asonantes. Cualquier rasgo de entusiasmo en realidad es una

\footnotetext{
${ }^{11}$ Hasta 1938, Santōka emprende reiteradamente viajes que tradicionalmente pertenecen a un entrenamiento budista que consistía en la emulación de los recorridos realizados por los hijiri (santos o monjes) o haijin como Bashō. Estos viajes cruzan una experiencia de la naturaleza con la de la modernidad. Estas, sumadas a su práctica del budismo Zen, son cruces bien identificados en su baiku. Incluso en sus Diarios Mendicantes (gyōkotsu nikeki) expresa con fatalismo el modo en que la naturaleza comenzó a verse intervenida por el proceso modernizador. En la entrada de su diario "Contando sobre mí" del 2 de febrero de 1931, Santōka escribe:
}

Un mundo conquistado, un periodo de lucha. Los humanos conquistan la naturaleza. Las personas derraman sangre luchando. Enemigos o aliados, ganar o perder, matar o ser matado. (...) Posiblemente, no está permitido que me siente dentro de mi choza en profunda paz. Además, yo, mi incompetencia e impotencia, soy responsable de esta Era del Error. Podría pararme en la vía pública a tocar la trompeta, pero no tengo fuerza de voluntad. Debo recluirme. En estos tiempos me sumerjo en un profundo pensamiento. El 'vacío' del mundo y la 'peregrinación religiosa' del yermo no pueden experimentarse en el exterior. Hay que regresar a la estupidez originaria y proteger esa estupidez. (Santōka, 2008). La traducción es nuestra.

12 Es pertinente comparar la poética de Santōka con la de Matsuo Bashō, quien no escribió baiku sino bokkeu, una forma poética anterior al haiku. Sin embargo, la obra de Bashō fue definitoria para la retórica del haiku. Por ejemplo, con respecto al uso del nombre propio, Bashō escribe: "Rueda del monte/ al mar, de Atsumi a Fuko, /la tarde fresca" O "Río Mogami:/ tomas al sol y al mar/ lo precipitas" (Bashō, 1981, p. 77). O bien, con referencias temporales precisas "El Quinto Mes, / sus caminos de lluvia:/ ¿dónde estará Kasajima? / Nos hospedamos en Iwanuma” (Bashō, 1981, p. 56). 
marca de pasividad y humildad. La forma de hacer la palabra en Santōka, de crear estos efectos sutiles, es a través de la develación del vacío de las cosas que ya no es trascendental ni divino, aun menos místico, sino que crea imágenes donde todo confluye para crear una imagen única y menor, una pequeña luz. Hay en Santōka un modo de convertir los espacios y objetos concretos en zonas sensibles. Por ejemplo, haciendo de la casa un espacio de luminosidad al ser la luz eso que destella y se destaca en el siguiente haiku:

\section{雪のあかるざが家いっぱいのしづけさ}

Yuki no akarusa ga

ie ippai no

shizukesa

La luminosidad de la nieve

llena la casa

en calma

(Santōka, 2006, p. 150)

En este haiku no hay verbo sino dos imágenes que se indiferencian. Una la luminosidad de la nieve y otra que se diversifica en dos sentidos: repleta de calma y derrotada de calma. Ambas imágenes afectan un espacio específico: $i e$, hogar o casa (que no refiere al espacio material sino al hogar simbólico). Si la segunda imagen describe la primera, la luminosidad ingresa en un plano activo: destruye un espacio (derrota, la sombra) o bien lo atiborra, lo repleta, sin dejar lugar para otra cosa. Pareciera que la luminosidad de la nieve alcanza la casa, la derrota y la llena a la vez. En este sentido, la luminosidad tiene un rasgo invasivo. Se trata de un matiz donde lo que pertenece 
a la naturaleza deviene como un carácter particular (es decir, el baiku no muestra la totalidad de la nieve como luminosidad, sino lo invasivo de esa luminosidad). Este matiz conduce al deshacimiento de los límites en los espacios en Santōka. La naturaleza rompe las barreras de un espacio como la casa. También, en este haiku:

\section{空あけて空いっぱいの春}

Mado akete

mado ippai no haru

Abriendo la ventana

a reventar de primavera

(Santōka, 2006, p. 133)

El kanji de ventana se compone de corazón-mente (es decir, kokoro), abertura y vacío. Pero ese vacío (ese umbral espacial que distancia el adentro y el afuera) al mismo tiempo conecta lo diferente: no puede estar sino habitado por el corazón, donde las cosas se suspenden. La primavera repleta y derrota aquello que la contenía: no solo la ventana de la casa (la que puede abrirse, mado akete) sino también la ventana que puede llenarse de manera indeterminada (mado ippai). Hay un pliegue entre las dos ventanas: la que deja pasar la primavera, la calidez del clima, la luz a la casa, y la que se llena con la experiencia temporal de la primavera (de la repetición, de lo que va a marchitarse), que es la ventana del sujeto personal. En este pliegue está la fisura de este haiku gracias al matiz que recibe el término mado en sus dos repeticiones. Quien abre la ventana es el guardián de la primavera: la estancia se revela como la experiencia temporal del espacio a través de la estación. El 
matiz no es la primavera llenando la casa sino la posibilidad de la primavera de invadir a quien le dé lugar, de derrotarlo con floraciones, de hacerlo un sujeto primaveral al punto de vaciarlo. Esto mismo puede observarse en:

\section{くりやまで月かげのひとりで}

kuriyama made

tsuki kage no

hitori de

Penetra la luz de la luna

hasta la cocina

Estoy solo.

(Santōka, 2006, p. 27)

El haiku comienza determinando un espacio específico, la cocina. Seguidamente, nombra lo apenas visible en ese espacio. Se trata de un pliegue entre dos sombras: una, tsuki kage, aquí traducido como luz de luna, pero que su significado literal es sombra de luna. El japonés no reconoce la cualidad lumínica de la luna sino su luz como sombra que emite en la noche. La sombra no es una región de oscuridad donde la luz está interrumpida, sino lo producido por la conjunción de un objeto lumínico y no-lumínico. Es decir, la luminiscencia de aquello que no posee la propiedad lumínica por sí mismo, pero que hace visible (o se hace visible) para el ojo humano las cosas. La sombra de la luna permite discernir en las tinieblas otra sombra, la de hitori, palabra que precedida por la partícula de (la que indica el medio o el lugar a través o donde se realiza una acción) inmediatamente debemos identificar como sustantivo, en este caso: una persona (antes que la cualidad de solo o soledad).

Nº. Segundo Semestre de 2018 
De este modo, en el pliegue de una sombra y otra se revela lo particular del baiku. Este hace ver, en la sombra de la luna, el volumen de otra sombra. Ella no le pertenece a nadie, configurando así un espacio de una existencia sin sujeto. Un espacio donde la naturaleza es testigo de existencias visibles, pero totalmente ignoradas por aquellos que la sostienen. Más explícitamente, escribe Santōka:

\section{茶の木かこまれそこはかとないくらし}

Cha no ki ni kakomare

sokohakatonai kurashi

Rodeado por arbustos de té,

llevando una existencia

anónima

(Santōka, 2006, p. 154)

La determinación espacial parece delimitada perfectamente al comienzo de este baiku con cha no ki kakomare, incluso esto se ve reforzado por la aparición de un yo afectado por la acción gracias a la terminación mare (rodeado). Sin embargo, inmediatamente esa precisión se borra con la expresión sokobakatonai kurashi. El término sokobakatonai es un adjetivo que significa débil, leve, vago, nebuloso, indeterminado. Este sentido deriva de la significación de esta palabra cuando es leída como frase: soko ba ka to nai, que puede traducirse como no bay algo. Kurashi, antes que existencia, significa condiciones materiales de vida o circunstancias de vida. Ante el reconocimiento de lo indeterminado de dichas circunstancias, el espacio, al principio definido claramente, comienza a difuminarse: la imagen de un sujeto rodeado por arbustos de té inmediatamente se difumina 
para mostrar que esos arbustos de té carecen de todo rasgo o singularidad, están igual de vacíos que el sujeto que escribe. Incluso, aunque parezcan acorralar al sujeto, comparten su vaciamiento y muestran que él es uno con las cosas.

La insistencia de Santōka está en la espera. Durante esta espera todo lo que ingrese en el espacio cobra singularidad de diversos modos. Por ejemplo, quien se sienta a esperar la muerte, agudiza el oído al punto de escuchar el aleteo de la mariposa, como en:

\section{てふてふひらひらいらかをこえた}

Chōchō hirahira iraka o koeta

La mariposa revoloteando ha pasado por encima de lo más alto del tejado (Santōka, 2006, p. 135)

El juego de este haiku consiste en hacer ingresar en el campo de lo audible la sutileza de lo visible. La romanización ha sintetizado el recurso onomatopéyico utilizado por Santōka: tefutefu es la lectura antigua del kanji de chōchō, considerada como una onomatopeya que refiere al aleteo de la mariposa. En este haiku, la tefutefu se combina con el uso de hirabira, onomatopeya que se utiliza tanto para las mariposas como para sonorizar el movimiento de los pétalos de cerezo cuando sopla el viento. Podríamos denominar a la primera parte de este baiku como un paisaje sonoro que describe el vuelo de la mariposa en ascenso hacia lo más alto del tejado o más allá del tejado. Pero lo interesante del haiku es la sutileza de este paisaje 
tefutefu birabira. Al re-trazarlo, invita a acentuar la fragilidad del vuelo de la mariposa que, impredeciblemente, asciende. El haiku enseña la fragilidad y la sutileza de ese vuelo, finalmente, de la existencia. Pero, además, el sonido del haiku da cuenta de que no-hay otra cosa más que eso, más que el vuelo, la talidad de la mariposa es el sonido del aleteo.

Así como el aleteo de la mariposa, la mudez de los arbustos de té, la campanilla que anuncia la dirección del viento o de la muerte pueden observarse en:

\section{山から風が風鈴へ生きていたいとおもふ}

Yama kara

kaze ga fûrin e

ikite itai to omou

Un viento que va

de la montaña a la campanilla...

Yo quiero seguir viviendo...

(Santōka, 2006, p. 181)

y

風鈴の鳴るさへ死のしのびよる

Fûrin no naru sae

shi no shinobi yoru

El simple tintineo

de la campanilla con el viento

Sigilosa se acerca muerte 
(Santōka, 2006, p. 168)13

En esta pareja de haiku hay nuevamente paisajes sonoros. En ambos haiku, el sonido está expresado por el término que designa campanilla: fürin, que significa campana de viento, un elemento decorativo tradicional japonés, utilizado en ventanas o puertas durante el verano. Típicamente japonés: la atenuación de la experiencia sensitiva de la brisa veraniega con el sonido de la campanilla. En fürin no naru sae, literalmente: tan solo el sonido de la campanilla; shi no shinobi yoru, el sigilo de la muerte en la noche. Si pensamos metafóricamente este baiku, podríamos pensar que: durante la agonía, el sonido mínimo de la campanilla anuncia la inminente muerte del cuerpo. Sin embargo, el matiz de este haiku está en lo sorpresivo: ante un débil sonido, el estremecimiento inmediato del cuerpo. El paisaje hace de lo audible algo que trasciende lo táctil, porque es el cuerpo el que teme dejar de escuchar la precisión del tintineo de la campana.

En yama kara... se hacen audibles dos tonos del sonido, uno grave de la montaña y uno débil de la campanilla. El sonido marca una dirección del viento, ya que literalmente el baiku dice: desde la montañal el viento/ hacia la campanillal creo querer seguir viviendo. El deseo con el que el haiku finaliza emerge de una experiencia auditiva del viento entre las cosas. La montaña y la campanilla se vacían para integrar una misma canción. Es decir, ambos se indiferencian en la melodía que narra el deseo

13 En ambos haiku, como puede observarse, la romanización del término fürin lleva macrón (diacrítico utilizado para indicar una vocal larga). Sin embargo, hemos decidido no utilizar esta romanización en cuerpo de texto dado que, en los diccionarios consultados, este término no posee vocal larga $(u u)$ correspondiente el fonema $\bar{u}$.

$N^{\circ}$ 9. Segundo Semestre de 2018 
de querer vivir. Se trata entonces de espacios sonoros donde el poeta experimenta el vacío de las cosas en una misma sinfonía. Una sinfonía sin director que comienza cuando en el baijin solo queda un oído que canta y una voz que escucha la canción que trae el viento o la tierra:

\section{ひとりたがやせばうたふなり}

Hitori tagayaseba

utau nari

Cuando trabajo la tierra

a solas

surge una canción

(Santōka, 2006, p. 34)14

\section{Consideraciones finales}

Este trabajo fue el ensayo de un modo de leer el baiku a partir de la categoría teórico analítica de re-trazar, la cual fue configurada a partir de consideraciones de la escritura y la traducción desde el pensamiento de la deconstrucción. En primer lugar, comenzamos delineando algunas de las nociones de la deconstrucción de Jacques Derrida. Para ello, vislumbramos en primera instancia las posibilidades de poner

14 Tagayaseba es el trabajo de cultivo de la tierra, pero lo que interesa de este haiku es el modo en que la canción surge. El verbo naru tiene un matiz especifico que tiene que ver con transformarse, con un hacer que tiene una causa anterior. En este sentido, lo que fulgura en este baiku es como desde la tierra la canción viene. Pareciera como si quien trabaja la tierra estuviera buscando la canción que le es propia. 
en relación la deconstrucción en un marco cultural nooccidental. Ello condujo a observar en el pensamiento derrideano un concepto de escritura acorde a las escrituras masivamente no alfabéticas, así como también delimitar los alcances de su origen pictográfico. Siguiendo a Derrida, comprendimos un concepto de escritura a partir del movimiento de la buella y su pertinencia para avanzar sobre el baiku. Seguidamente, encontramos necesario el desarrollo de una dimensión fundamental para avanzar sobre la escritura japonesa: la traducción. Esto permitió vislumbrar la necesidad de comprender que la condición de legibilidad del baiku se encuentra en lo intraducible del texto. Por esta razón la categoría de re-trazar consistió en volver a trazar los baiku, comenzando por el desmontaje de los trazos para luego reunirse articulando sentido inéditos, configurando paisajes sonoros, y observando los modos singulares de articulación de lo sensible. Puede afirmase que la poética de Santōka revela las composiciones y los sentidos menos esperados, los cuales muchas veces son utilizados en distintas direcciones en los baiku de nuestro haijin. Cada uno de los matices, de las fisuras, de las arrugas de los haiku han apuntado a diferentes rasgos de la poética de este haijin, así como a su contemporaneidad con un conjunto de procesos culturales que asedian su escritura. Además, hemos podido comprobar el modo en que la escritura de Santōka y el uso de la escritura japonesa es fundamental para la escritura del haiku. Esta revela las composiciones y los sentidos menos esperados, los cuales muchas veces son utilizados en distintas direcciones. El re-trazo de los haiku citados ha permitido observar que ese haijin se encuentra 
alojado en la intemperie: lugar que no hay que ir a encontrar sino hacer presente en la escritura, ya sea en el vuelo sin dirección de la mariposa o en los imprevisibles anuncios de la muerte.

\section{Referencias Bibliográficas}

Bashō, M. (1981). Senda hacia tierras hondas. Barcelona: Seix Barrial.

Cuartas Restrepo, J. M. (2005). Los 7 poetas del haiku. Calí: Programa Editorial Universidad del Valle.

Derrida, J. (1986). De la gramatología. Ciudad de México: Siglo XXI Editores.

(1995). Che cos'è la poesia?. Trad: José Perednik. En: Xul (11). Pp. 42-44.

(1994). La différance. En Márgenes de la filosofía. Madrid: Cátedra.

(1996). El monolingüismo del Otro. Buenos Aires: Manantial.

(1997). La diseminación. En La diseminación. Madrid: Editorial Fundamento.

(2001) La lengua no pertenece. Entrevista con Évelyne Grossman. En: Europe (número consagrado a Paul Celan), Año 79, $\mathrm{N}^{\circ}$ 861-862, enero-febrero de 2001. Traducción de Ricardo Ibarlucía publicada en Diario de Poesía, $\mathrm{n}^{\mathrm{o}}$ 58, primavera de 2001. Recuperado de: https://redaprenderycambiar.com.ar/derrida/textos/celan.ht $\underline{\mathrm{m}}(15 / \mathrm{O} 3 / 2019)$ 
(2016). Torres de Babel. En Invenciones de lo otro. Buenos Aires: La Cebra.

(2016). Carta a un amigo japonés. En Psyché: invenciones de lo otro. Buenos Aires: La Cebra.

Santōka, T. (2009). El monje desnudo. Madrid: Miraguano. (2008). 私を語る[Contando de mí]. Recuperado de: https://www.aozora.gr.jp/cards/o00146/files/48267 31582. html (15/03/2019) 